\title{
EDITORIAL
}

\section{The health of our educators and HIV/AIDS}

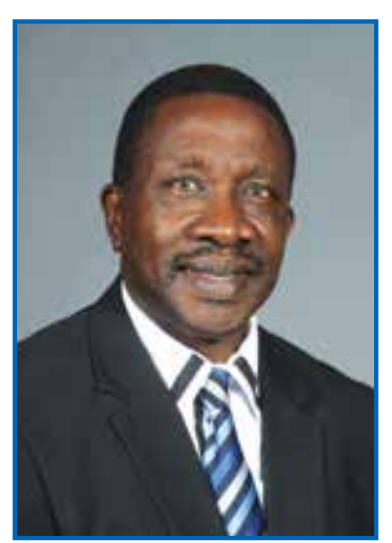

In 2005, the Human Sciences Research Council (HSRC) of South Africa published a research report titled: The Health of Our Educators: A focus on HIV/AIDS in South African public schools (2004/2005). The findings of the report were shocking as the health of our educators was a source of concern because of the HIV prevalence recorded. The results documented that $12.7 \%$ of the educators who gave specimens for HIV testing were HIV positive. This included educators in all provinces, and educators of all ages, sex and racial groups. ${ }^{1}$

The study further indicated that HIV prevalence among educators was highest in those aged 25-34 years (21.4\%), followed by those aged 35-44 (12.8\%). Educators residing in rural areas and those working in rural schools had higher HIV prevalence than educators residing in urban areas and teaching in urban schools. ${ }^{1}$ The implication is that if nothing is done to stem the tide, the rural schools that struggle to attract teachers will be worse off as the number of educators diminish. The authors alluded that determinants for the HIV prevalence among the educators were multiple, namely behavioural, knowledge deficit, lack of selfefficacy skills, migratory practices, gender, and alcohol misuse. Chronic conditions such as hypertension, stomach ulcers, arthritis and diabetes were common. The report concluded that our country was likely to lose a very high proportion of educators due to job dissatisfaction, job stress and low morale.

A recent follow-up study conducted by the same HSRC in 2014 and released on 16 June 2017 showed that South Africa had over 400000 teachers, according to the Basic Education Department 2014 statistics. A high number of teachers at public schools are living with HIV, suffering from job-related stress, physically sick and do not know about government's HIV strategy in schools. Most of the teachers are black, unmarried or widowed women who work or live in poverty-stricken rural areas. The HSRC randomly sampled 1380 public schools across the country. The results showed that at least 58000 teachers were living with HIV (14.5\% HIV prevalence), mostly in the $34-44$ age group. ${ }^{2}$

The report further highlights that KwaZulu-Natal recorded the highest prevalence followed by Mpumalanga and the Eastern Cape, while Western Cape was the least affected. About $55 \%$ of the teachers were on antiretrovirals (ARVs). Due to their illnesses,
$66.6 \%$ of teachers took advantage of their sick leave. About $11.8 \%$ of the teachers indicated they had two or more sexual partners, and $37.4 \%$ reported using condoms with non-regular partners. Some $6.3 \%$ of the teachers were HIV positive but did not know of their status. The study further showed that while government had put HIV strategies in place at schools, many teachers were not aware of them. Many other teachers sampled were suffering from emotional and physical illnesses such as hypertension, TB and diabetes. $^{2}$

We now have two HSRC reports on our educators and HIV/ AIDS over a 10-year period. The question to ask is: "What has changed in the Department of Basic Education's strategy to reduce the prevalence of HIV/AIDS among educators?" The South African National Department of Health runs the largest HIV/AIDS programme on antiretroviral drugs in Sub-Saharan Africa for those who are infected. However, it appears that our educators who should know better are not doing enough to prevent the spread of the infection. The teacher union (SADTU) indicates that the union had its own HIV programmes to help test teachers around the country. So what is wrong with that strategy? Noone seems to know that such a programme is running as its marketing is poor. The more we lose teachers the more the strain is felt on our educational system, especially in the rural provinces and rural schools where the HIV prevalence is highest according to the two HSRC studies.

We need to prevent new HIV infections among our educators and to improve their health status and working conditions. This will involve urgent collaboration between the national departments of Basic Education and Health on implementing appropriate strategies. These will include sexual behaviourchange programmes, increase in knowledge of HIV transmission, focus on rural schools with high HIV prevalence among educators, discourage migratory practices among educators and set up workplace health programmes to address the co-morbid chronic conditions. There is a health (HIV/AIDS) crisis among our educators and we cannot wait for another HSRC research report before decisive actions are taken.

\section{Prof. Gboyega A Ogunbanjo}

Editor-in-chief: SAFPJ

\section{References:}

1. Shisana O, Peltzer K, Zungu-Dirwayi N, Louw J. The Health of Our Educators: A focus on HIV/AIDS in South African public schools. 2005 (accessed on 16 June 2017). Available from: http://www.hsrcpress.ac.za/full_title_info.asp?id=2082

2. Sifile L. Teachers burdened by stress and HIV. Sowetan Live. 2017 (accessed on 16 June 2017). Available from: http://www.sowetanlive.co.za/news/2017/06/16/ teachers-burdened-by-stress-and-hiv 